\title{
सोलन जनपद की संस्कृति में संगीत एवं संस्कार का महत्त्व प्रियंका
}

शोधार्थी, संगीत विभाग, हिमाचल प्रदेश विश्वविद्यालय, समरहिल, शिमला

सार

हिमालच प्रदेश को देवभूमि के नाम से जाना जाता है। हिमाचल प्रदेश के 12 जिलों में सोलन क्षेत्र अपनी एक अलग छवि प्रस्तुत करता है। सोलन अपनी ऐतिहासिक छवि के साथ धार्मिक पर्यटन स्रिथ प्राकृतिक पर्यटन स्थलों के लिए प्रसिद्ध है। संस्कृति, सामाजिक जनजीवन की सभ्यता का दर्पण होती है। आज के प्रचलित संस्कारों से ही उस समाज की संस्कृति बनती ही, जो कि उस समाज की जीवन शैली की परिचायक होती है। लोगों के रहन, सहन आदि से लेकर रीति-रीवाज़, धर्म, मेले, त्यौहर, लोक नृत्य, लोक नाट्य, लोक गीत, साहित्यकला आदि सभी संस्कृति के अंग और संस्कृति शब्द संस्कृत भाषा से लिया गया है। संस्कृत और संस्कृति दोनों ही शब्द संस्कार से बने है संस्कार का अर्थ है- कुछ कृत्यों की पूर्ति करना। मनुष्य जन्म से अनेक प्रकार के संस्कार करता है- जिसमें उसे विभिन्न प्रकार की भूमिकाएं निभानी पड़ती है, जिनके द्वारा वह अपने जीवन के उदेश्यों की पूर्ती करता है। भारतीय धर्मशास्त्र में 16 संस्कारों का वर्णन है। मनुष्य जन्म पूर्व से मृत्यु बाद तक इन संस्कारों से बंधा रहता है। संगीत और संस्कार का आपस में घनिष्ठ सम्बन्ध है। जितने भी मानव द्वारा संस्कार किए जाते हैं वह सभी संस्कार संगीत के बिना अधूरे प्रतीत होते है। संस्कार गीतों में जन-जीवन की आत्मा निवास करती है। इन विभिन्न संस्कारों के अवसर पर स्त्रियां अपने कोमल कंठ से गीत गा कर जन मन का मनोरंजन किया करती है। संस्कार गीतों के माध्यम से किसी भी क्षेत्र की संस्कृति को आसानी से जाना तथा समझा जा सकता है। वर्तमान समय में आज वे ही संस्कार सम्पन्न होते है जो उल्लासयुक्त है, अन्य सभी अनुष्ठानिक रह गए है। कुंजी शब्द -संस्कृति, संस्कार, संगीत, जन्मोत्सव, विवाहोत्सव।

भूमिका

हिमाचल प्रदेश को देवभूमि के नाम से जाना जाता हे, और इसे देवभूमि की संज्ञा अकारण ही प्राप्त नहीं हुई है। इसका पुष्कल प्रमाण वैदिक लौकिक साहित्य में उपलब्ध होता है। हिमाचल प्रदेश भारतवर्ष का एक राज्य है। स्वतन्त्रता प्राप्ति से पूर्व हिमाचल प्रदेश छोटी-छोटी रियासतों और ठकुराईयों में विभक्त था। सोलन बघाट रियासत की राजधानी थी। इसमें आठ रियासतें सम्मिलित थी। जिसमें बघाट, बाघल (अर्की), महलोग, कुठाड़, बेजा, हण्डूर (नालागढ़), कुनिहार तथा क्योंथल शामिल थे।

स्वतन्त्रता प्राप्ति के पश्चात हिमाचल का निरन्तर गठन और पुनर्गठन होता रहा। फलस्वरूप इसका विस्तार चार जिलों मण्डी, चम्बा, महासु और सिरमौर से बढ़कर 12 जिलों में हुआ और 1972 ई0 में सोलन ज़िला अस्तित्व में आया।

हिमाचल प्रदेश के 12 ज़िलों में सोलन क्षेत्र अपनी एक अलग छवि प्रस्तुत करता है। किसी भी स्थान विशेष के नामकरण के साथ कोई न कोई ऐतिहासिक या पौराणिक घटना जुड़ी रहती है। सोलन नामकरण के संदर्भ में मान्यता है कि इस शहर का नामकरण यहां की अधिष्ठात्री देवी शूलिनी के नाम पर हुआ है। नगर अधिष्ठात्री भगवती मां शूलिनी वर्षों से कंठहार बनी हुई है। सोलन अपने ऐतिहासिक छवि के साथ धार्मिक पर्यटन स्थित प्राकृतिक पर्यटन स्थलों के लिए प्रसिद्ध है। यहां की ऐतिहासिक परम्पराएँ, सांस्कृतिक धरोहरें आज भी नई पीढ़ी के लिए प्रेरणा स्त्रोत बनी हुई है। सोलन शहर प्रकृति की गोद में स्थापित एक आलौकिक स्थान है। यहां के असंख्य देवी-देवता सनातनी अरिमिता के प्रतीक 
है। मां शूलिनी जो शक्ति के अनेक रूपों की एक अभिव्यक्ति है। यहीं व शक्ति है जो शव को शिव बनाती है। यही पालक है, यही संहारक है।

संस्कृति, समाजिक जनजीवन की सभ्यता का दर्पण होती है। आज के प्रचलित संस्कारों से ही समाज की संस्कृति बनती है, जो कि उस समाज की जीवन शैली की परिचायक होती है। लोगों के रहन-सहन आदि से लेकर रीति-रिवाज़, धर्म, मेले, त्यौहार, लोकनृत्य, लोकनाट्य, लोकगीत, साहित्यकला आदि सभी संस्कृति के अंग है। हिमालयीन संस्कृति भारतवर्ष की संस्कृति का मूलाधार है। मानव मन, आचार, रूचियों को जो मांजता है, शुद्ध करता है वह संस्कृति है।

सम्बन्धित साहित्य का अध्ययन

पूर्व में किए गए अवलोकन का पता लगाने के लिए साहित्य का अध्ययन अत्यधिक महत्त्वपूर्ण होता है। मानव केवल एक ऐसा प्राणी है जो सदियों से एकत्र किए गए ज्ञान का लाभ उठा सकता है। मानव ज्ञान के तीन पक्ष होते है- ज्ञान को संचित करना, ज्ञान को दूसरे तक पहुंचाना तथा ज्ञान में बढ़ोतरी करना। यह तथ्य शोध में विशेष रूप से महत्त्वपूर्ण है।

डॉ. रामस्वरूप शांडिल द्वारा लिखी गई पुस्तक "हिमाचल प्रदेश के लोक संगीत की परम्पराएं (सोलन जनपद के संदर्भ में)" सोलन क्षेत्र के लोकगीतों की विभिन्न गायन शैलियों व नृत्य से सम्बन्धित गीतों, जिनमें सांस्कारिक गीत, ऋतु गीत एवं त्यौहारों से सम्बन्धित गीत, शृंगारिक गीत इत्यादि की जानकारी उपलब्ध है।

कुलदीप सिंह द्वारा लिखी गई पुस्तक "हिमाचल प्रदेश का लोक-जीवन" में लोक संस्कृति, लोक संस्कार, लोक धर्म व लोक विश्वास से सम्बन्धित तथ्य प्राप्त होते है।

अनुसंधान क्रियाविधि

विषय चयन

शोधार्थी को संगीत में विशेष रूची रही है। प्रस्तुत विषय को चुनने का कारण, शोधार्थी को बचपन से ही संगीत वं संस्कृति को जानने की जिज्ञासा रही है। शोधार्थी अर्की क्षेत्र की मूल निवासी है। इस क्षेत्र की सांस्कृतिक परम्पराओं की मूल में व्याप्त को अधिक निकट से जांचने व परखने की लालसा ने शोधार्थी को इस विषय पर कार्य करने के लिए प्रोत्साहित किया।

\section{शोध कार्य का उद्देश्य}

शोध कार्य को सफल बनाने की कुंजी उसके निर्धारित लक्ष्य एवं उद्देश्य पर आधारित है। शोध कार्य की योजना में क्रमबद्धता सिर्फ उद्देश्य के निर्धारण से ही संभव हो सकती है, इसलिए इस शोध पत्र का उद्देश्य सोलन जनपद की संस्कृति में संस्कार व संगीत का क्या योगदान है।

शोध प्रविधि

शोध कार्य की सामग्री संग्रह करने के लिए विविध उपकरणों का प्रयोग शोध में किया जाएगा। इस शोध कार्य के लिए निम्नलिखित विधियों द्वारा सामग्री एकत्रित की गई।

1. पुस्तकें 2. इंटरनेट 
लोक संस्कृति का महत्त्व अनुपम है। "वस्तुतः यह वह व्यावहारिक ज्ञान है जो सहस्त्रों वर्षों से परम्पराओं का अनुशीलन करते हुए परिपक्व हुआ है।" सोलन क्षेत्र के लोकाचार, लोकविश्वास, लोक मान्यताएं अपने आप में अनूठी है। सोलन जनपद में संस्कृति का व्यापक स्वरूप है। यहां की संस्कृति पहाड़ों के आंचल में पूर्णरूपेण सजीव है। प्रत्येक लोकगीत, लोक कथा, लोकगाथा, बुझावणी या कहावत किसी न किसी रूप में संस्कृति को संजोए हुए है। लोकगीतों में जहां हास्य विनोद की अपूर्व छटा और हास्य व्यंग्य एवं करूणा का अद्भुत मिश्रण है, वही लोक, बुझावणी कहावतें मनोरंजक एवं ज्ञानवर्धक है। नारी के गिद्दे में, दादा, दादी की कहानियों में, बांसुरी की धुन में और कलाकार के मूक चित्र में संस्कृति का रहस्य छुपा हुआ है, अतः संस्कृति एक ऐसा कोश है जिसके बिना मानव मूल्य शून्य है। यह किसी व्यक्ति विशेष की धरोहर न होकर समूचे समाज का खजाना है, जिसकी रक्षा करना प्रत्येक का सामान दायित्व है। संस्कृति का सम्बन्ध मनुष्य के अतीत, वर्तमान, भविष्य की जीवन पद्धति से है जो मानव के वर्तमान को अनुशासित कर भविष्य को सर्वमंगल की भावना से प्रेरित करती है। सोलन जनपद की संस्कृति मिश्रित संस्कृति है जिस पर आस-पास की क्षेत्रीय संस्कृतियों का प्रभाव स्पष्ट झलकता है। लोक साहित्य के विविध आयाम इसके वाहक है। जिन्होंने यहां की संस्कृति को समृद्ध बनाने में अपना अमूल्य योगदान दिया है।

संस्कृत और संस्कृति दोनों ही शब्द संस्कार से बने है। संस्कार का अर्थ है- कुछ कृत्यों की पूर्ति करना। मनुष्य जन्म से ही अनेक प्रकार के संस्कार करता है-जिसमें उसे विभिन्न प्रकार की भूमिकाएं निभानी पड़ती है, जिनके द्वारा वह अपने जीवन के उद्देश्यों की पूर्ति करता है, अतः संस्कार एक परिमार्जन की प्रक्रिया है जिसे मनुष्य उम्र पर्यंत करता रहता है। ये संस्कार मानव जीवन के अनेक पक्षों से जुड़े होते है, जैसे नैतिक, ऐतिहासिक और सामाजिक।

नीति के क्षेत्र में संस्कार का संबंध नैतिकता, सच्चाई, ईमानदारी, आदर्शों, नियमों एवं सद्गुणों से है। यहां संस्कृति का संबंध सत्यं, शिवं सुन्दरं से है।

ऐतिहासिक पक्ष में संस्कार का संबंध धर्म, ज्ञान, विज्ञान, कला, संगीत, दर्शन एवं साहित्य से संबंध है।

सामाजिक क्षेत्र में संस्कार का संबंध विश्वास, मान्यताएं, कानून, आचार-व्यवहार, रीति-रिवाज़, मनोरंजन, आनंद आदि से है।

पूर्व जन्म, परम्परा, कुल-मर्यादा, शिक्षा, सभ्यता इत्यादि का मन पर पड़ने वाले प्रभाव का नाम संस्कार है। संस्कार मन की रूचि, आचार-विचार आदि को परिष्कृत और उन्नत करने का कार्य करते है। सरल शब्दों में कहें तो परम्परा से चला आया हुआ कोई ऐसा कृत्य जिसका किसी विशेष अवसर के लिए विधान हो उसे संस्कार कहते है।

भारतीय परम्परा में सोलह संस्कारों का विधान है। मनुष्य जन्म पूर्व से लेकर मृत्यु तक इन संस्कारों से बंधा रहता है। भारतीय लोक जीवन परम्परा में जिन सोलह संस्कारों का उल्लेख है, वे है:- "गर्भाधान, पुंसवन, सीमंतोनयन, जातकर्म, नामकरण, निष्क्रमण, अन्नप्राशन, चूड़ाकर्म या मुण्डन, विवाह, कर्णबेध, वानप्रस्थ, यज्ञोपवीत, वेदारंभ, संन्यास, सामावर्तन और अंत्येष्टि।" ये सभी लोक संस्कार मनुष्य जीवन के विशिष्ट अवसरों के लिए होते है और कतिपय विशिष्ट अवसरों पर ही कार्यन्वित होते है। 
हमारे संस्करों के दो पक्ष है- शास्त्रीय पक्ष एवं लोकपक्ष। "शास्त्रीय पक्ष के कई विधान अब लुप्त हो गए है तथा गर्भाधान, पुंसवन और सीमन्तोत्रयन संस्कार अब नहीं होते। जातकर्म, अन्नप्राशन एवं निष्क्रमण थोड़े-बहुत भेद के बाद संपन होते है। लोकपक्ष शास्त्रीय पक्ष की भांति महत्त्पूर्ण है। शास्त्रीयपक्ष के अनुसार जहां पुरोहित द्वारा संस्कार संपन्न कराया जाता है, वहीं लोकपक्ष में ये संस्कार स्त्रियों द्वारा संपन्न किये जाते है। भले ही भारतीय संस्कारों का आधार शास्त्रीय है परन्तु बहुलता प्रायः लोक संस्कारों की है जो सामाजिक मान्यता प्राप्त लोकाचार कहलाते है, जैसे कुल देवता का पूजन, स्थानीय शक्ति पीठों में जातर ले जाना तथा स्थानीय मन्दिरों में बच्चों का मुण्डन संस्कार करवाना इत्यादि। सोलन जनपद के जनसमुदाय का सामाजिक जीवन शुरू से ही संगीतमय रहा है। प्रत्येक मंगलकार्य में संगीत का प्रमुख स्थान होता है। विभिन्न संस्कारों के अवसर पर स्त्रियां अपने कोमल कंठ से गीत गा-गा कर, जन-मन का अनुरंजन किया करती है। इन गीतों को पारंपरिक आस्था से गाया जाता है। इसी कारण इसमें परिवर्तन भी नहीं हो पाया। वर्तमान समय में बदलते सामाजिक, सांस्कृतिक परिवेश तथा आर्थिक स्थिति के कारण लोगों में संस्कारों के प्रति विशेष उल्लास नहीं दिखाई देता। जन्मोत्सव व विवाहहोत्सव में तरह-तरह के गीत गाए जाते हैं। जन्म और विवाह ये दो संस्कार अत्यन्त महत्त्वपूर्ण है। इन अवसरों पर लोकमानस सुख और आनन्द से परिपूर्ण रहता है। इस समय गाये जाने वाले गीत मंगलगीत कहलाते है। इन दोनों संस्कारों के अन्तर्गत अनेक संस्कारों का उल्लेख आता है, यथा जन्मसंबंधी संस्कारों के अन्तर्गत, नामकरण, चूड़ाकरण, अन्नप्राशन, मुण्डन आदि संस्कार आते है। विवाह संस्कार में कई प्रकार की रस्म निभाई जाती है। अनुष्ठान की दृष्टि से यद्यपि मृत्यु संस्कार का बहुत महत्त्व है किन्तु इस संस्कार में शोक का भाव प्रबल होता है। "वेदों में मृत्युसंबंधी ऋचाएं मिलती है। मृत्युसंबंधी लोकगीत नहीं मिलते है। इस अवसर पर गाये जाने वाले गीतों में निर्गुण पदों को लिया जा सकता है।"

सोलन जनपद में जन्म से लेकर मृत्यु तक के अससरों पर संस्कार गीत गाए जाते है। जिन संस्करों पर ये संस्कार गीत गाए जाते है वे मुख्यतः दो प्रकार के है :-

1. जन्म संस्कार

2. विवाह संस्कार

1. जन्म संस्कार

भारतीय संस्कृति में नारीत्व की पूर्णता मातृत्व से मानी गई है, अतः नारी के लिए मां बनने का असवर अत्यन्त महत्त्वपूर्ण एवं आहदकारी होता है। यद्यपि जन्म संस्कार का अर्थ पुत्र जन्म ही नहीं है अपितु पुत्री जन्म भी जन्म संस्कार के अन्तर्गत आता है। पुराने समय की बात की जाए तो पुत्री की अपेक्षा पुत्र को सदैव महत्त्व दिया गया है। राजाओं के समय में पहले पुत्र उत्पति पर अधिक खुशियां मनाई जाती थी, जिसका प्रत्यक्ष संकेत यहां के सांस्कारिक गीतों से प्राप्त होता है। वर्तमान समय में पुत्र एवं पुत्री दोनों के उत्पन्न होने पर खुशियां मनाई जाती है।

जन्म संस्कार पर मंगलामुखी स्रित्रयों द्वारा बधाई गीत गाए जाते है। गीतों में शिशु के माता-पिता को बधाई दी जाती है। शिशु और उसकी माता को गीतों के माध्यम से दीर्घ आयु की कामना की जाती है। शिशु का जन्म श्री राम के सदृश माना जाता है और यह कामना की जाती है कि बच्चा श्री राम जैसा 
गुणवान, पितृभक्त और मर्यादा पालन करने वाला बने। बधाई गीत को स्थानीय भाषा में पिहाई, भ्यायी गीत कहा जाता है।

होम संस्कार

जब शिशु ग्यारह अथवा तेरह दिन का हो जाता है तब उस दिन हवन कराया जाता है, जिसे स्थानीय भाषा में होम कहते है। इस क्षेत्र में यह प्रथा भी है कि जब तक शिशु ग्यारह या तेरह दिन का न हो जाए और हवन द्वारा गृहा शुद्धि न हो जाए तब तक गांव के अन्य लोग उस घर के लोगों को छुते नहीं इसे स्थानीय भाषा में सुतक कहा जाता है। यहां के लोगो की मान्यता है कि जितने भी शुभ कार्य व देवताओं की पूजा के लिए शुद्ध नहीं माना जाता है। हवन के बाद ही गृह शुद्ध एवं वस्त्र आदि की शुद्धि होती है। इस दिन भी महिलाएं बधाई गीत गाती हैं।

छठो संस्कार

होम संस्कार के पश्चात् छठो संस्कार अथवा अन्नप्राश्न होता है। जब शिशु छ: महिने का हो जाता है तब कोई भी शुभ दिन निर्धारित कर उत्सव का आयोजन किया जाता है। इस दिन बच्चे को पहली बार अन्न खिलाया जाता है। इस संस्कार उत्सव पर भी महिलाओं द्वारा भ्यायी व बधावो का गायन किया जाता है।

मूंडन संस्कार

मूंडन हिन्दुओं का मुख्य संस्कार है। इसे संस्कृत में चूड़ाकर्म कहते है। केश गुच्छ, केशपाश, जूटिका, चूड़ा आदि समानार्थक है। धर्मशास्त्रों के अनुसार संस्कार व्यक्ति के लिए दीर्घायु, सौंदर्य इस संस्कार का प्रयोजन था। मूंडन सोलह संस्कारों में एक प्रसिद्ध संस्कार है। इस संस्कार के पहले बालक के बालों का काटना निषिद्ध है। यह बच्चे की आयु के पहले, तीसरे, पांचवे या सातवें वर्ष में पूर्ण किया जाता है। बच्चे को मामा की गोद में बिठाया जाता है, उसके पश्चात् नाई द्वारा बच्चे के बाल कोटे जाते है। बच्चे के बाल डोरी से बांध कर लाल कपड़े में सम्भाल कर रख दिये जाते हैं और समय मिलने पर उन्हें किसी कुल देवता या देवी या अन्य तीर्थ स्थान पर चढ़ाने के लिए रख लिया जाता है। कई बार यह संस्कार ही किसी देव-मन्दिर या तीर्थ स्थान पर पूर्ण किया जाता है। इस समय महिलाओं द्वारा विभिन्न प्रकार के भ्याली, गीतों व बधावों का गायन किया जाता है। सभी लोगों को भोजन करवाया जाता है।

सोलन जनपद में शिशु के जन्मोत्सव पर मंगलामुखियों व स्थानीय स्त्रियों द्वारा गीत गाए जाने का प्रचलन है जिसे पियाई व बधाई गीत कहा जाता है।

पियाई गीत

सथायी : हसणू खेलणू घर आये, रण झूंझण माये।

अन्तरा : सुनियारा दे घर जाये-2, कंगणू तंदिरा लाये हसणु खेलणू घर आये।

भावार्थ : इस गीत में पुत्र उत्पन्न होने पर प्रसन्नता व्यक्त करते हुए हंसने खेलने का वर्णन आता है। हंसने खेलने के लिए घर में नया खिलौना आया है। इसलिए घर के सभी सदस्य अपने कार्य में व्यस्थ है। शिशु की मां कह रही है कि सुनियार के पास जा कर बच्चे के लिए कंगणु लेकर आओ। 
2. विवाह संस्कार

मनुष्य के जीवन में विवाह का बड़ा महत्त्व है। हिन्दू धर्म में सोलह संस्कारों का विधान है। इन सोलह संस्कारों में विवाह संस्कार सबसे महत्त्वपूर्ण है। इस संस्कार के द्वारा युवक व युवती नये जीवन में प्रवेश करते है। विवाह सर्वाधिक मंगल और उत्साह का अवसर माना जाता है। विवाह संस्कार अत्यन्त धूमधाम से मनाया जाता है। जितनी धूमधाम से कोई भी संस्कार सम्पन्न नहीं होता है। विवाह से सम्बन्धित लोक गीतों का क्षेत्र अत्यन्त व्यापक है। विवाह का सम्बन्ध वर और कन्या दोनों पक्षों से है, अतः सामान्यतः इन गीतों का वर्गीकरण दोनों रूपों में किया जाता है। दोनों ही पक्षों में विवाह की रसमें सात दिन पहले प्रारम्भ की जाती है। दोनों पक्ष गणेश जी की स्थापना करवाकर रस्मों का प्रारम्भ कर देते है। तेल, हल्दी, उबटन आदि अनेक मांगलिक कृत्य नित्य प्रति होते रहते है। कन्या पक्ष के गीतों में विविधता अधिक होती है। इस क्षेत्र में दोनों प्रकार के विवाह उत्सवों में गाए जाने वाले अनेक लोक गीत प्रचलित है। इस संस्कार पर प्रायः स्त्रियों द्वारा ही गीत गाए जाते है।

सोलन जनपद में गाए जाने वाले कुछ संस्कार गीतों का वर्णन शब्दों सहित किया जा रहा है।

तेल गीत : विवाह में सर्वप्रथम वर व वधू को तेल डाला जाता है, जिसे स्थानीय भाषा में 'तेल-पडना' कहते है। इस अवसर पर सुहागिन स्त्रियां वर या वधू को तेल डालते हुए लोक गीत गाती है जिसमें वर या वधु के मंगलमय सुख समृद्धि युक्त दीर्घजीवी होने की कामना की जाती है

सथाई : तेलियां विरन तेल लैयावे, रलमिल मंगल गाईये।

अन्तरा : माये सुहागण तेल पावे, रलमिल मंगल गाईये।

चाची सुहागण तेल पावे, रलमिल मंगल गाईये।

ताई सुहागण तेल पावे, रलमिल मंगल गाईये।

बटणा गीत : यह गीत वर-वधू को उबटन लगाते समय गाया जाता है। यह गीत वर-वधू दोनों पक्षों में समान रूप से गाया जाता है।

स्थाई : बा-बा कटोरा बटणे दा-2

मलदियां दो जणियां-बा-मलदियां दो जणियां।

अन्तरा : बा-बा लाड़े री आमा तेलिया

बा-बा-बा कटोरा मलदियां दो जणियां

बा-बा कटोरा बटणे दा।

स्नान गीत : यह गीत वर-वधु को नहलाते समय स्त्रियों द्वारा गाया जाता है।

स्थाई : आंगण चिकड़ किन्ने बे किया

किन्ने डोलया पाणी। 
अन्तरा : अम्मा दा लाडला / लाडली नहावे धोवे

उन्ने डोलया पाणी।

शान्ति पूजन गीत : यह गीत शांत पूजा के समय गाया जाता है। यह गीत वर व वधु दोनों पक्षों में समान रूप से गाया जाता है।

स्थाई : शांतिये बैठे पुरोहिता तैनू क्या बे चाहिदा।

अन्तरा : शांतिये बैठे जजमानणिये मैनू फूल बे चाहिदा।

सेहरा बन्धी गीत : विवाह के गीतों में सेहरा बन्धी का विशेष महत्त्व है। जब दूल्हे को सेहरा बांधा जाता है, तो वह दृश्य अत्यन्त मनमोहक इसलिए लगता है क्योंकि सभी लोग दुल्हे को सेहरे सहित बड़े आकर्षण से देखते है। यह गीत केवल वर पक्ष की तरफ से गाया जाता है। जिस गीत का वर्णन दिया जा रहा है इसे बन्ना गीत भी कहा जाता है।

स्थाई : सेहरा बने लाल, खूब बनायो।

सेहरा बने लाल।

अन्तरा : जुग-जुग जीवे मामा जो तेरा-2

जीने तेरे सिर पर-2

सेहरा बंधायो-2

सेहरा बने लाल।

सुहाग (विदाई गीत) : विवाह की समस्त रीतियों से सम्पन्न होने पर विदाई का विदारक क्षण आता है। विदाई के समय माता-पिता, भाई-बहन तथा परिवार के लोगों का हृदय धैर्य की सीमा को तोड़ देता है। कन्या की माता के त्याग, स्नेह तथा ममता की अभिव्यक्ति इन संस्कार गीतों में मिलती है। बेटी का अलग होना मां-बाप के लिए असहनीय हो जाता है। जब कन्या ससूराल जाने लगती है उस समय के गीतों में जो करुणा भरी होती है उससे संसार के विरक्त लोगों के हृदय भी पसीज जाते हैं। उस समय गाया जाने वाला गीत इस प्रकार से है।

स्थाई : नीवी नीवी होया मुइये, कालिये धारे

देखी लेणा बापू जी दा देश बे।

अन्तरा : छाड़ी देणी अम्मा तेरी राम रसोई

छाड़ी देणी बापू जी दा देश बे।

छाड़ी देणी ताई तेरी राम रसोई

छाड़ी देणी ताया जी दा देश बे।

यह सभी गीत सोलन जनपद में विवाह संस्कार के अन्तर्गत गाए जाते है। 
मृत्यु संस्कार : सोलन जनपद में जहां एक ओर जन्म तथा विवाह संस्कार मनाए जाते है वही दूसरी ओर मृत्यु संस्कार को भी विशेष रूप से निभाया जाता है। मृत्यु से सम्बन्धित सभी संस्कारों को पूरे विधि विधान के साथ किया जाता है।

\section{निष्कर्ष}

सोलन जनपद में विशेषकर हिन्दू धर्मावलम्बियों में संस्कारों का विशेष महत्त्व है। यहां का जनजीवन जन्म से लेकर मृत्यु तक सोलह संस्कारों में विभाजित है। सामाजिक जनजीवन में प्रत्येक संस्कार की अपनी मान्यता और प्रचलन है जो दिन-प्रति-दिन घटते जा रहे है। मानव जीवन का मूल तत्त्व संतुलन है जो अंतर्भव की शांति और प्रसन्नता से आता है इसे बनाये रखने के लिए ही संस्कार आयोजित किए जाते है। परिवर्तन संसार का नियम है। चाहे ऋतु चक्र हो या जीवन चक्र दोनों में संतुलन स्थापित करने और उपद्रव से बचने के लिए मनुष्य अनेक प्रकार के संस्कार, यज्ञ और अुनष्ठान करते हैं। लोकगीत मानव जीवन के अनिवार्य अंग है जो जीवन के मान्य संस्कारों से जुड़े। प्रत्येक संस्कार का प्रारम्भ और अंत गीत के साथ होता है। इन गीतों में स्थानीय प्रभाव और बोली के कारण गायन शैली में अन्तर आ जाता है। खुशी के गीतों में मंगल कामना, दीर्घायु और समृद्धि की याचना की जाती है। इसलिए कहा जा सकता है सोलन जनपद की संस्कृति में संगीत एवं संस्कारों का विशेष योगदान रहता है।

संदर्भ ग्रंथ सूची

शर्मा देवराज, हिमाचल प्रदेश (भौगोलिक, ऐतिहासिक एवं आर्थिक परिचय), पृ०- 139, जगत प्रकाशन, घुमारवी, बिलासपुर, प्रकाशन, 1993 ।

सिंह कुलदीप, हिमाचल प्रदेश का लोक जीवन बनाम लोक संस्कृति, पृ०- 38, 39, 41, प्रमेशवरी प्रकाशन बी-109, प्रीत बिहार दिल्ली-110092, प्रथम संस्करण-2008।

शर्मा, गोकुल चन्द, हाटेश्वरी माता पौराणिक परिचय, गगन प्रिंटिग प्रैस ठियोग, ज़िला शिमला। 